\title{
Prevalence of Gastrointestinal Parasites in Yaks of Lehe VDC, Manaslu Conservation Area
}

\author{
Reena Byanju ${ }^{1}$, S.P. Shrestha ${ }^{2}$ and D.R. Khanal ${ }^{2}$ \\ ${ }^{1}$ Nepal Academy of Science and Technology (NAST), Khumaltar, Lalitpur \\ ${ }^{2}$ Animal Health Research Division, Khumaltar, Lalitpur \\ e-mail:reenabyanju1@gmail.com
}

\begin{abstract}
Qualitative analysis of 44 fecal samples of yaks from Lehe VDC of Manaslu Conservation Area showed the positive result in 36 samples (81.82\%). Strongyle showed the highest infection (47.23\%) while the least was with Amphistomum (8.34\%). Infection with Trichuris, Ascaris, Eimeria and Coccyx were also reported in the present study. The pattern of infection was both mixed (52.78\%) and single (47.23\%).
\end{abstract}

Key Words: Ascaris, GI parasites, prevalence, Strongyle, Trichuris

\section{Introduction}

Yak is Himalayan cattle, native to Himalayan region of Nepal, Bhutan, China and India. It is the only domestic animal which survives and thrives in high Himalayas and is found in alpine and subalpine zone where flat lands with extensive grassy meadows exist. In different parts of the world, yak farming has been recognized as an important source of income for various pastoral tribes in the remote areas in many countries including Nepal.

Gastrointestinal parasitic (GI) infection in livestock including yak is very common. The economic losses due to parasitic infection are numerous (Newton 1995) causing morbidity and sometimes also mortality in the animals which have direct impact upon the livelihood of people. GI parasites degrade their health resulting decrease in production of quality milk, meat and hair product (Waller 2002). Since parasites have significant impact upon on the health and nutrition of their host, the identification and further treatment of the parasites is a must for increasing the productivity of yak.
Researches on gastrointestinal infection in yaks are being conducted in various parts of the world especially in Bhutan, China, India and Nepal. Joshi (1982) has reported the incidence of liverfluke in both yak and their cross breeds with cattle in many villages of Nepal. Similarly Weiner et al. 2003 have found out Fasciola hepatica, Echninococcus cysts and nematodes in yaks of Nepal.

A number of studies on the gastro-intestinal nematode fauna of yak have been performed in various parts of the world, such as in China (Hogg 2004, Yunfeil et al. 2004), India (Katiyar et al. 1981, Rai et al. 1989, Ansari et al. 1989, Yadav et al. 2007, RangaRao et al. 1994, Bandyopadyay et al. 2010, Rahaman et al. 2010), Bhutan (Wangdi 1996) and Tibet (Liu 1994). As expected, a comprehensive array of species have been reported, representing the range of important nematode, trematode and cestode species commonly found in bovine and ovine hosts, some being apparently yak-specific ( Waller 2002). One incidence 
was reported by Yadav et al. 2007 for the isolation of Parafilaria bovicola from yak of Arunanchal Pradesh of India which is the causative agent of verminous haemorrhagic dermatitis. Some studies have also reported the helminthic infection in the Bhutanese yaks (Wangdi 1996) and Tibeten yaks (Liu 1994).

Moreover no documented record of yak GI parasites of the cited area has been reported thus the present study will identify the occurrence of the parasites that can be a useful tool for the control of parasitic diseases having at Lehe VDC which might have direct impact upon the yak production.

\section{Methodology}

\section{Study Area and Sample Collection}

Sample collection was done during October 2010 in the Lehe VDC around Hinang gumba of Manaslu conservation area which is located at an altitude of 11831 feet and $28^{\circ}(\mathrm{N}), 84^{\circ}(\mathrm{S})$. A total of 44 fresh fecal samples were collected and were placed in a zip lock poly bag to which few drops of $10 \%$ formalin soaked in cotton was added as a preservative. The samples were then stored in a cool and dark area and brought to laboratory for further analysis.

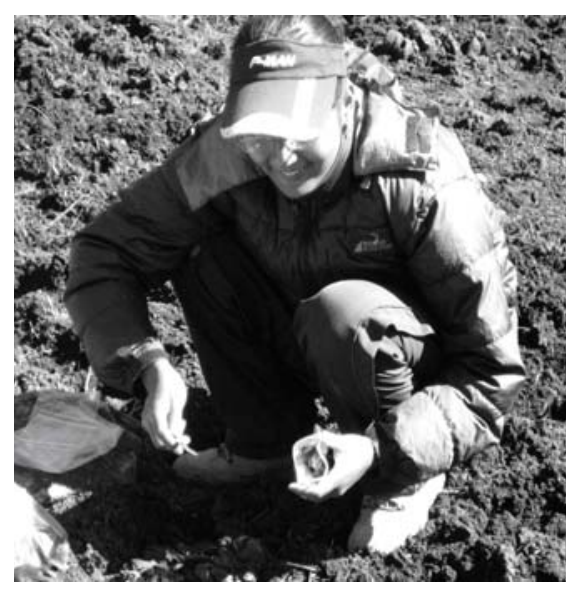

\section{Sample Analysis}

Collection of fecal samples All samples were analyzed qualitatively (sedimentation and differential floatation method) in the lab for the presence of gastrointestinal parasite.

\section{Results and Discussion}

Faecal sample examination showed the total prevalence of $81.82 \%$ (36/44) with 52.78\% (19/36) mixed infection and $47.23 \%(17 / 36)$ single infection. Strongyle infection was reported to be maximum i.e. 47.23\% (17/ 36) which is similar to the study performed by RangaRao et al. (1994) and Rahaman et al. (2010). Ascaris infection was reported to be $41.67 \%$ (15/36), coccidian parasites (Eimeria) 38.89\% (14/36), Trichuris $30.56 \%$ (11/36), Fasciola 19.45\%(7/36) and Amphistomum 8.34\% (3/36). Eimeria, Trichuris and Strongyle were also reported in a study performed by Hogg (2004) while presence of Fasciola has been reported by Weiner et al. (2003). Since the yaks found in Lehe VDC are similar to all the domesticated yaks in other parts of the world thus the parasites reported were also in accord with the researches performed by different researchers. The presence of GI parasites have significant impact upon the health of yak, thus interfering their growth, so further researches on yak parasites need to be undertaken to determine the prevalence of zoonotic diseases and their impact on yak and their hybrids for their healthy development and increase production. Determination of the prevalence of parasites can help yak herders and veterinary professionals in making recommendations for treatment, control and pasture rotation to limit parasitic burdens and consequently increase productivity of yak.

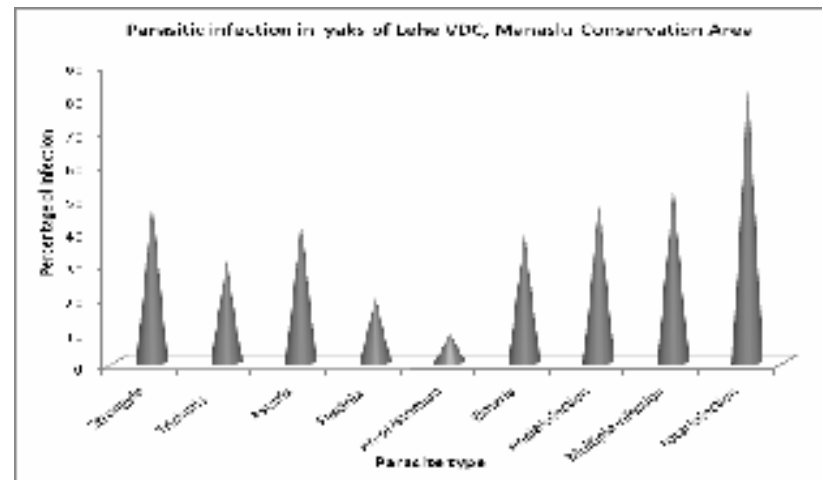

Fig. 1. Percent prevalence of gastrointestinal parasitic infection in yaks of Lehe VDC, Manaslu Conservation 


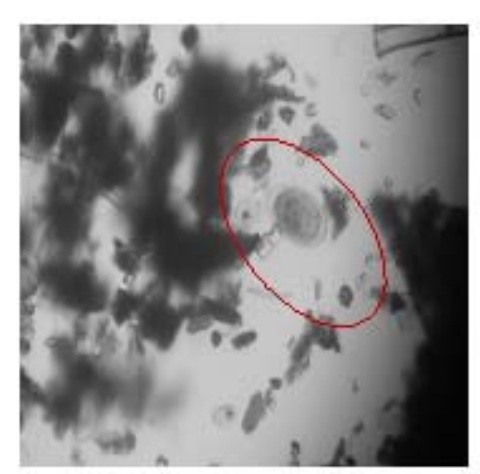

$\mathrm{E}_{\mathrm{gg}}$ of Ascaris

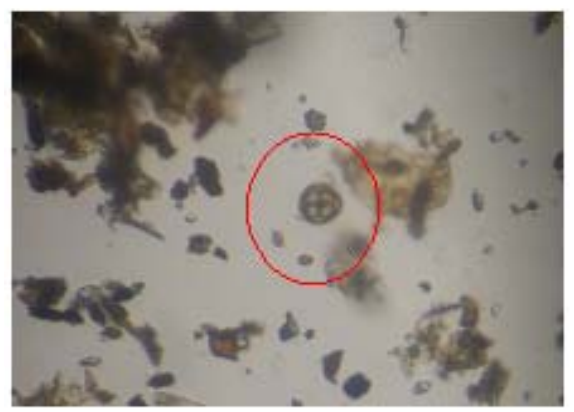

Egg of Eimeria

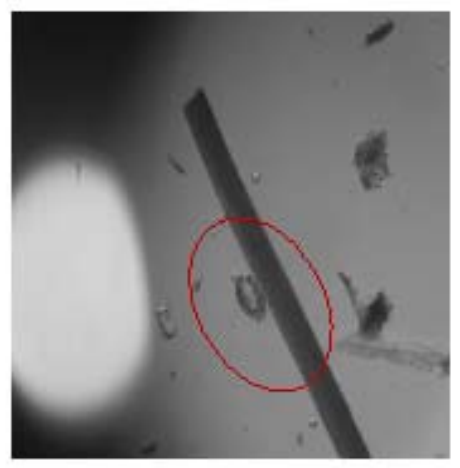

Egg of Fasciola

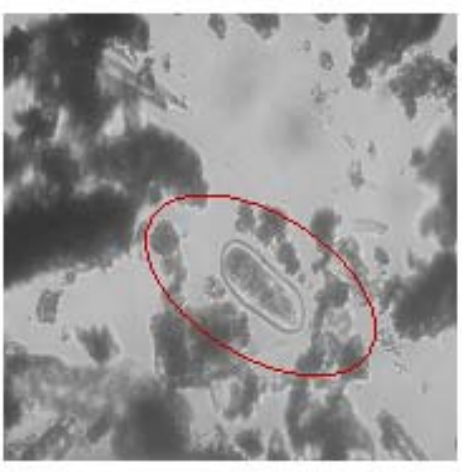

Egg of Strongyle

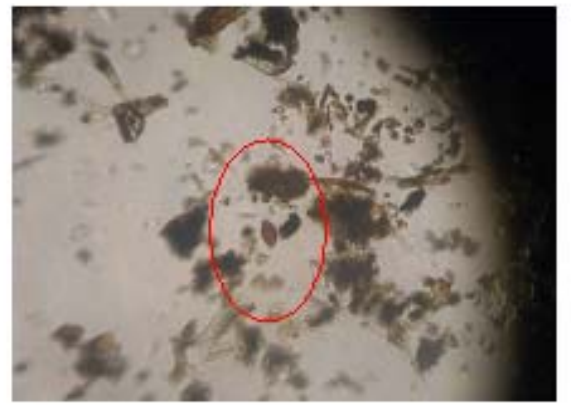

Egg of Trichuris

Fig.2. Eggs of different parasite

\section{Acknowledgements}

The authors acknowledge cooperation extended by Mr. Babu Lal Kuwar of Animal Health Research Division, Khumaltar, Lalitapur for lab analysis and Ms. Chhewang Dorje Lama and the people of Lehe VDC for their helping hand during fecal samples collection. The present study was carried out as a part of NAST thematic research program at Manaslu Conservation Area.

\section{References}

Ansari, M.Z., M.K. Rai and H.U.S. Chauhan. 1989. Pathology of liver, lung and caecum of yak (Bos poephagus) infected with Dicrocoelium, Fasciola, Echinococcus and Trichuris. Indian Journal of Animal Sciences 59: 552-554.

Bandyopadyay S., P. Pal, D. Bhattacharya, A. K. Bera, D. Pan and H. Rahman. 2010. A report on the prevalence of gastrointestinal parasites in yaks (Bos poephagus) in the cold desert area of North Sikkim, India. Tropical Animal Health Production 42: 119-121.
Hogg, K. 2004. Internal parasites of yak (Bos poephagus) of the Gannan, Gansu Province, P.R. China. In: Proceedings of Fourth International Congress on Yak, Chengdu, China.

Joshi, D.D. 1982. Yak and Chauri husbandry in Nepal. H.M. Government Press, Singha Durbar, Kathmandu, 17: 145pp.

Katiyar, R.D., V.K. Srivastava R.C., Khera, and S.B. Sinha. 1981. Incidence of Helminthes in Domesticated yaks (Bos poephagus) in Sikkim. Livestock Research 1: 115118.

Liu W.D. 1994. Observation on growth-decline rule of roundworm and its larva in yak stomach and intestine. In: Proceedings of the 1st international congress on yak held in Lanzhou (September 4-9, 1994), Lanzhou (Eds. Zh. Rongchang, H. Jianlin and W. Jianping). Supplement of Journal of Gansu Agricultural University, Lanzhou, China, pp. 339-343.

Newton, S.E. 1995. Progress on vaccination against Haemonchus contortus. International Journal for Parasitology 25: 128-9. 
Rahman H., P. Pal and S. Bandyopadyay. 2010. Occurrence of gastrointestinal parasites in domesticated yaks in Sikkim. The Indian Journal of animal sciences 80: 3

Rai, M.K., M.Z. Ansari, B.N. Sahai, and V.S. Chauhan. 1989. Prevalence of helminth parasites of yak (Bos poephagus) in Sikkim, India, detection of secondary hydatidosis and histopathology of hydatid cysts parasitizing liver and lungs. Rivista di Parasitologia 50: 79-87.

RangaRao, G.S.C., R.L. Sharma and Haemapresanth. 1994. Parasitic infections of Indian Yak (Bos poephagus) grunniens- and overview. Veterinary Parasitology 53: 75-82.

Waller, P.J. 2002. Reindeer (Rangifer tarandus) and yak (Bos (Poephagus) grunniens): Disparate animal species - similar environment, management and parasite problems? In: Proceedings of the $3^{\text {rd }}$ international congress on yak held in Lhasa (September 4-9, 2000), Nairobi (Eds. H. Jianlin, C. Richard, O. Hnnotte, C.
McVeigh and J.E.O Rege). International Livestock Research Institute, Nairobi, Kenya, pp. 429-438.

Wangdi, P. 1996. Survey of gid eradication program: incidence of coenurosis in yak population at Lingshe dungkahg. Yak Newsletter 2: 12-24.

Weiner, G., H. Jianlin and L. Ruijun. 2003. The yak (second edition). Regional Office for Asia and the Pacific of the Food and Agriculture Organization of the United Nations: Bangkok, Thailand. 22: 460

Yadav, S.C., B.C. Saravanan, S. Borkataki, and K. Baruah. 2007. A record of Parafilaria bovicola from yak (Poephagus grunniens, L.) in India. Journal of Veterinary Parasitology 21: 37-38

Yunfeil, Y., W. Hongning, L. guangrong, and T. Bing, 2004. Epidemiological survey and control of enterozoic diseases of yak and Tibetian sheep in the Sichuan westnorth grassland. In: Procee dings of fourth international congress on yak, Chengdu, China. 